MARTIN NEIL BAILY

Brookings Institution

ALOK K. CHAKRABARTI

Drexel University

\title{
Innovation and Productivity in U.S. Industry
}

WHAT IS THE ROLE of innovation in productivity growth, and to what extent has a change in either the pace or the character of innovation contributed to weak productivity growth in the past fifteen years? We have collected new data on innovation that support the view that a slowing of innovation played an important part in the decline in productivity growth.

We report here the first stage in an in-depth investigation of productivity in particular industries. This first stage focuses on two manufacturing industries, chemicals and textiles. Certainly, more industries are needed to verify the findings, but the two industries chosen provide a good contrast. The chemical industry is capital-intensive and processbased, and relies heavily on its own research and development. The textile industry is less capital-intensive, uses an equipment-based technology, and relies primarily on externally generated innovations. ${ }^{1}$

In addition to collecting innovation data, we interviewed managers,

Helpful comments by Brookings Panel members and by Mike Scherer are acknowledged. Research assistance at Brookings was provided by Nathaniel S. Levy, who also prepared extensive background material on the textile industry. Research assistance at Drexel was provided by K. R. Gundala, Christine Schillings, Russell Lavery, and Richard Dorfman. This study has been supported in part by grant no. SRS 8509346 from the National Science Foundation to Drexel University.

1. According to the Business Week R\&D Scoreboard (July 8, 1985), pp. 86-106, the chemical companies in their survey spent $\$ 3.7$ billion on R\&D in 1984, representing 3.1 percent of sales, or $\$ 4,250$ per worker. The textile and apparel industries spent $\$ 81.5$ million on $R \& D$, which was 0.8 percent of sales and $\$ 571$ per worker. 
engineers, and scientists in the two industries about the relationship between innovation and productivity and about other possible causes of slow productivity growth in the $1970 \mathrm{~s}$. We conclude that although innovation was an important part of the story of the slowdown, structural shocks also retarded growth.

\section{Direct Measurement of Innovation}

Innovations in production technology begin with a "fishing expedition," an attempt to see whether progress is possible. The project may be stimulated by an advance in basic science, but more often it is simply a search for a new and better way to apply existing scientific knowledge. If successful, the initial search process will lead to an invention, and the invention may result in one or more patents.

Not all such inventions are developed to the point of commercial introduction. Many are discarded because they are not expected to lead to successful new products and processes. For those that are carried forward, the bulk of the total research and development (R\&D) cost is incurred after the invention stage, and there is a substantial lag before a new product or process is ready for commercial introduction. ${ }^{2}$ It is at the point of commercial introduction that the new product or process is described as an innovation.

\section{PROCESS INNOVATIONS}

New processes are developed for a variety of reasons-to make new products, to produce with lower levels of pollution, to save energy, or, most important, to improve productivity. New plants that incorporate the new productivity-enhancing technology or existing plants that are modified to use the new technology will have a higher level of productivity than will plants with older technology. Obviously the new technology does not take over right away-the level of productivity does not jump. But the availability of the new technology provides the means by which productivity growth can take place. We expect, therefore, that the larger

2. According to officials at the Du Pont Company, 90-95 percent of R\&D costs are incurred after the idea or invention has been formulated. 
is the flow of process innovations, the higher is the rate of productivity growth.

\section{PRODUCT INNOVATIONS}

Process innovations are not the only or even the main source of productivity enhancement for U.S. manufacturing as a whole. New products supplied to an industry from outside and new products developed within an industry also improve productivity. The most obvious example is new equipment developed by the machinery industry and supplied to another industry. For example, in the 1970s new textile equipment developed by the European and Japanese machinery industries replaced the mechanical shuttle with air or water jets and brought about dramatic productivity benefits. Such innovations will always raise labor productivity. In practice they raise multifactor productivity also, because when the stock of capital of an industry is computed, the machinery is priced in such a way that part of the innovation in the machinery-producing industry is attributed to multifactor productivity growth in the machinery-using industry. ${ }^{3}$

New products produced within an industry also enhance its productivity. In the period after a new product is introduced, productivity rises rapidly as the scale of production increases and the company moves down a learning curve. New products may also indicate new process developments. In the chemical industry, where product and process innovations are closely related, much of the $R \& D$ cost associated with a new product is spent on developing the process used to produce it.

As price indexes are now constructed by the Bureau of Labor Statistics, not all of the productivity improvement resulting from new product development is reflected in official productivity measures. Initially, a new product is excluded from the output price index. It is linked into the index once it is established. The dollar value of the production of new products is counted right away, however, so that nominal output always includes new products. In computing real output for productivity purposes, therefore, nominal output, including new

3. F. M. Scherer discusses the effect of innovation in supplying industries on productivity in using industries. See "Using Linked Patent and R\&D Data to Measure Interindustry Technology Flows," in Zvi Griliches, ed., R\&D, Patents and Productivity (University of Chicago Press, 1984), pp. 417-61. 
products, is deflated by a price index that excludes at least some of these products.

The nature of the product cycle in most industries is that old products have a standard technology and profit margins are gradually squeezed by competition. New products are typically introduced with higher margins. These high margins are then effectively counted as high real output, so that the introduction of new products increases measured productivity. On the other hand, new products usually have declining relative prices, because of the learning curve and rapid productivity gains. And until the new product is linked into the price index, the direct effect of this is missed. However, since a typical new product is just a variant of an old product, the old products do have to compete with the new products. The rapid productivity gains that occur for new products also hold down the prices of old products and, hence, reduce inflation in the industry price index even if it excludes these new products.

Without more information it is impossible to be sure of the size of the new-product bias in productivity measurement. New products do increase measured productivity, but it is likely that the increase as now measured is somewhat understated relative to a true economic measure of productivity. ${ }^{4}$

\section{COLLECTING THE INNOVATION DATA}

In view of the complexity of the innovation process, the question is where to go to collect data on innovations and what innovations to include. Previous studies of innovation have emphasized only the big breakthroughs. ${ }^{5}$ But small, incremental innovations can be equally important. A breakthrough innovation-the shuttle-less weaving machine-was available by the 1970 s, but could not be used throughout the textile industry until successive generations of new machinery had been developed that both perfected the technology and adapted it to produce the great variety of fabrics that the industry makes. The new machinery developed over fifteen years or more made up a near-constant flow of equipment innovations that contributed to productivity growth.

Our decision was to collect a file of innovations for the two industries

4. Without implicating him in our conclusions, we would like to thank Jack E. Triplett, until recently at the Bureau of Labor Statistics, for a helpful conversation on this issue.

5. Gellman Research Associates, Inc., Indicators of International Trends in Technological Innovation, Study prepared for the National Science Foundation (Washington, D.C., April 1976). 
selected, chemicals and textiles, using the trade periodicals that serve each. ${ }^{6}$ New products developed within the industry and supplied to the industry are both advertised and described extensively in articles in these journals. New processes are also noted and described, if not always advertised. Although companies frequently keep secret the details of new process technology, the existence of a process innovation and some information about its character generally are reported. We doublechecked our findings with industry engineers to learn whether our search procedure had missed significant innovations, particularly new process developments.

Our research assistants were graduate students at Drexel University who had at least undergraduate training in chemical or textile engineering. We trained them in the selection criteria described below, and monitored their performance.

Although the assistants knew of the general goals of the project, no one involved had a preconceived view that innovation either had or had not slowed after 1973. In previous work, Baily had argued that factors other than innovation were responsible for the productivity slowdown. ${ }^{7}$ Chakrabarti, who supervised the data collection, is primarily interested in the management aspects of innovation and how corporate strategies towards innovation are determined.

Based on advice from chemical engineers at Drexel and in the industry, we established four categories of chemicals innovation (products, processes, equipment, and instruments) and set up criteria for judging whether a new item in fact represented something significantly new or improved. We tracked innovations originating both within and outside the industry. We judged new chemical products to be innovations if they were chemically new (that is, had new physical or structural properties), a significant modification of an existing chemical, or chemically reformed or recompounded for different applications. A new chemical process had to show changed inputs or yields or produce a new product. An equipment innovation, often incorporated into new processes, had to operate at new physico-chemical parameters or process new materials. A new instrument had to be able to measure with greater precision, in a

6. For chemicals, the periodicals covered were Chemical Engineering, Chemical Engineering Progress, Chemical Engineering News, and Chemical Week. For textiles, the journals were Textile World, Textile Industries, American Dyestuff Reporter, Textiles Colors and Chemicals, and America's Textile Reporter.

7. Martin Neil Baily, "Productivity and the Services of Capital and Labor," BPEA, l:1981, pp. $1-50$. 
changed environment, or over a wider range, the operation of chemical processes.

The textile innovations were similarly classified and filtered, based on advice from textile engineers at the Philadelphia College of Textiles. The industry develops a small number of process innovations for dyeing and finishing, which use process technologies similar to those in the chemical industry. The principal way in which innovations improve productivity in the textile industry is through new textile machinery. We judged new equipment to be an innovation if it showed improvements over existing equipment in such characteristics as speed of operation, ability to handle new materials, or reduced input requirements.

Instrument innovations in dyeing and finishing are also similar to those described in the chemical industry. Instruments are used, too, in spinning and weaving, where they can sense the characteristics of the fiber and control the machinery to allow more rapid operation and less breakage.

Innovations in textile material inputs, which consist of new fibers, finishes, and dyes, overlap with the chemical product innovations. Most of these inputs come from the chemical industry, although separate chemicals are frequently combined into finishes and dyes within the textile industry. Product innovations take the form of new yarns and fabrics.

Our coverage of innovations was rather comprehensive. For the period 1967-82, we found 574 process innovations and 2,773 new products in the chemical industry and 2,047 equipment innovations in textiles. Once the innovations had been collected, we asked the chemical and textile engineers to review the files, report on the completeness of our coverage, and rank the innovations by technical importance. This ranking process is still going on. We report, below, rankings on some of the more important innovation categories.

\section{Innovation and Productivity}

The chemical industry, defined as SIC 28, but excluding the drug industry (SIC 283), achieved rapid multifactor productivity (MFP) growth until 1973, when growth slowed substantially. Unadjusted for capacity utilization, it slowed even more after 1979, as shown in table 1.

If MFP is to be linked to innovation, however, it makes sense to adjust 
Table 1. Multifactor Productivity Growth in Chemicals and Textiles, Selected Periods, 1965-83

Percent per year

\begin{tabular}{cccc}
\hline \multirow{2}{*}{$\begin{array}{c}\text { Industry } \\
\text { and series }\end{array}$} & \multicolumn{3}{c}{ Period } \\
\cline { 3 - 4 } & $1965-73$ & $1973-79$ & $1979-83$ \\
\hline Chemicals & & & \\
$\quad$ Unadjusted & 3.09 & 1.73 & 0.98 \\
$\quad$ Adjusted $^{\mathrm{b}}$ & 3.10 & 1.91 & 2.53 \\
Textiles & & & \\
$\quad$ Unadjusted & 2.61 & 3.37 & 3.18 \\
Adjusted $^{\mathrm{b}}$ & 2.73 & 3.56 & 3.38 \\
\hline
\end{tabular}

Source: Data provided by the U.S. Bureau of Economic Analysis and U.S. Bureau of Labor Statistics.

a. Multifactor productivity growth is calculated as the rate of growth of GDP originating in each industry minus the weighted average of the growth rates of the capital and labor inputs.

b. The adjusted growth rates are calculated by multiplying the capital input by the Federal Reserve Board's industry-specific measure of capacity utilization.

for capacity utilization changes. The rate of capacity utilization for the chemical industry has declined sufficiently over time, especially since 1979 , to affect the measure of productivity. An adjusted growth rate for capital input to the industry can be constructed by multiplying the capital stock by the capacity utilization rate reported in industry-specific Federal Reserve Board series. This procedure provides a better estimate of capital services actually used. The measure of MFP growth calculated from the adjusted capital input is shown in table 1. Even with the adjusted measure, it remains true that growth slowed substantially after 1973. But, as a result of the adjustment, we now see that there was some recovery of growth in 1979-83. Excess capacity in this industry, it seems, brings about a substantial drop in productivity performance.

Table 1 shows that the textile industry experienced no productivity slowdown at all after 1973. There was, in fact, some acceleration. Moreover, the capacity adjustment makes only a minor difference to the productivity numbers in textiles. One reason is that the industry had no widespread excess capacity, as reported in the FRB series. Another is that since the industry is not very capital-intensive, a given amount of excess capacity has only a small effect on multifactor productivity.

\section{CHEMICAL INNOVATIONS}

Table 2 reports the basic data on innovations in the chemical industry. The pace of innovation slowed considerably from 1967-73 to 1974-79, 
Table 2. Innovations in the Chemical Industry, Selected Periods, 1967-82

Average number per year

\begin{tabular}{lcccc}
\hline Period & $\begin{array}{c}\text { Chemical } \\
\text { products }\end{array}$ & $\begin{array}{c}\text { Chemical } \\
\text { processes }\end{array}$ & Equipment & Instruments \\
\hline $1967-73$ & 332.0 & 39.0 & 107.9 & 29.6 \\
$1974-79$ & 38.8 & 32.3 & 56.7 & 18.2 \\
$1980-82$ & 64.7 & 34.7 & 104.7 & 54.0 \\
\hline
\end{tabular}

Source: Authors' computations. See text description.

with the number of product innovations falling by 215 percent, process innovations by 18 percent, equipment innovations by 64 percent, and instrument innovations by 49 percent. $^{8}$ This is the kind of dramatic decline in innovation that one would expect to see, given the decline in productivity growth that took place in the industry.

The one series that does not fit well with the overall picture of declining innovation and productivity growth is the number of chemical process innovations. Based on other information, we suspected that the numbers in table 2 might be understating the decline in significant, productivityenhancing process innovations after 1973. Certainly the numbers are called in question by a U.S. Department of Commerce report on the plastics and synthetic materials industry (a major part of the chemical industry) that concludes: "A major factor underlying the evolution of the industry's input structure between 1958 and the early seventies was the great wave of cost-saving technical advances which swept over the industry before 1970 . . . . However, it is also important to note that after 1970 , the industry developed and widely dispersed only one major costsaving innovation.",9

We do not agree with the Commerce Department's precise statement, but the idea that there was a wave of innovations in the 1960s that did not persist in the 1970s was confirmed for us by industry experts. We therefore evaluated the process innovation data carefully to determine whether there had been changes in the quality or the character of the innovations that might alter the picture provided by the crude numerical count of innovations in table 2. Many of the process innovations in the file are not clearly productivity-enhancing. Many have an environmental

8. These figures are calculated as 100 times the difference in the natural logs of the two numbers.

9. U.S. Department of Commerce, The U.S. Plastics and Synthetic Materials Industry Since 1958 (Government Printing Office, 1985), pp. 88-89. 
Table 3. Process Innovations in the Chemical Industry, by Type, Selected Periods, 1967-82a

Average number per year

\begin{tabular}{cccc}
\hline & \multicolumn{3}{c}{ Type of innovation } \\
\cline { 2 - 4 } Period & $\begin{array}{c}\text { Productivity- } \\
\text { enhancing }\end{array}$ & $\begin{array}{c}\text { Environment- } \\
\text { related }\end{array}$ & $\begin{array}{c}\text { Energy- } \\
\text { related }\end{array}$ \\
\hline $1967-73$ & 7.3 & 8.9 & 0.3 \\
$1974-79$ & 4.2 & 7.0 & 3.5 \\
$1980-82$ & 7.3 & 8.0 & 4.7 \\
\hline
\end{tabular}

a. The innovations were classified by the authors. The three categories above are not exhaustive. The remaining process innovations were primarily to produce a new or modified product. A few innovations could not be classified.

aim-to reduce the toxic pollution emitted by existing process technologies. Many more change the character or quality of the product. A number conserve energy. These last are productivity-enhancing, of course, but will not have a full impact on measured multifactor productivity, given that energy inputs are still valued in 1972 dollars.

Table 3 gives data on the number of process innovations that can be identified as being productivity-enhancing, environment-related, or energy-related. It is striking both how few productivity-enhancing process innovations there were and how much greater their post-1973 drop-off (55 percent) was than the total decline in process innovations (18 percent).

The table shows the importance of the environmental movement and anti-pollution efforts, but does not provide evidence that they were a major cause of the post-1973 slowdown. Over the whole period, more innovations were directed towards reducing pollution than towards productivity enhancement. But there were actually more environmentrelated process innovations before 1973 than there were from 1974 to 1979.

The energy-related innovations show exactly the pattern to be expected. There were almost no innovations in this area before 1973, but several afterwards. The diversion of R\&D effort towards saving energy may have contributed to the reduction of innovations that save capital and labor. ${ }^{10}$

Our next step was to ask the chemical engineers who had advised us initially to go over the file to rank the innovations by technical impor-

10. This hypothesis has been emphasized by Dale W. Jorgenson, "Energy Prices and Productivity Growth," Scandinavian Journal of Economics, vol. 83, no. 2 (1981), pp. $165-79$. 
Table 4. Process Innovations in the Chemical Industry, by Technical Importance, Selected Periods, 1967-82

Average number per year

\begin{tabular}{|c|c|c|c|c|c|c|}
\hline \multirow[b]{2}{*}{ Period } & \multicolumn{3}{|c|}{ Productivity-enhancing } & \multicolumn{3}{|c|}{ All processes } \\
\hline & $\begin{array}{l}\text { Radical or } \\
\quad \text { major } \\
\text { importance }\end{array}$ & $\begin{array}{c}\text { Significant } \\
\text { improvement }\end{array}$ & $\begin{array}{c}\text { Minor } \\
\text { importance }\end{array}$ & $\begin{array}{l}\text { Radical or } \\
\text { major } \\
\text { importance }\end{array}$ & $\begin{array}{c}\text { Significant } \\
\text { improvement }\end{array}$ & $\begin{array}{c}\text { Minor } \\
\text { importance }\end{array}$ \\
\hline $1967-73$ & 0.6 & 4.1 & 2.6 & 3.1 & 22.7 & 13.1 \\
\hline $1974-79$ & 0.3 & 2.8 & 1.0 & 2.7 & 15.8 & 13.8 \\
\hline $1980-82$ & 0.7 & 5.7 & 1.0 & 2.3 & 23.7 & 8.7 \\
\hline
\end{tabular}

Source: Authors' computations.

tance, according to whether they were radical, or major; a significant improvement; or minor, or imitative. ${ }^{11}$ As table 4 shows, the quality rankings do not change the picture much. ${ }^{12}$ The data in the table on productivity-enhancing innovations slightly weaken the case that innovation declined, for they show that the falloff in minor productivityenhancing innovations was greater than the decline in significant improvements. The falloff in radical and major innovations, however, was even larger than the decline in total productivity-enhancing innovation shown in table 3 . And when all process innovations are considered, the quality ranking strengthens the case for a decline. The number of minor innovations per year actually increased in 1974-79.

We also obtained quality rankings for the chemical product innovations to see whether the overall decline in product innovation shown in table 2 might simply reflect a falling off of minor changes. Table 5 indicates that this is not the case. As one would expect, the vast majority of all product innovations are fairly minor, but all three rankings showed a precipitous decline. Only one major product innovation occurred after 1973, according both to our file and to the engineer who did most of the rankings.

The Period 1980-82. Although the period 1980-82 consists of only three years and encompasses two sharp recessions, the data nevertheless show signs of a recovery in process and equipment innovation in the

11. Rankings were provided for us by Dipak Roy and William Herring, Amoco Chemicals; Edward Hogan, The PQ Corporation; Deepak Agarwal, Stearns Catalytic; R. Mutherasan and Elihu Grossman, Drexel University.

12. The work of Samuel Hollander on the chemical industry indicates that small process innovations may be as important to productivity growth as large ones. See The Sources of Increased Efficiency: A Study of Du Pont Rayon Plants (MIT Press, 1965). 
Table 5. Product Innovations in the Chemical Industry, by Technical Importance, Selected Periods, 1967-82

Average number per year

\begin{tabular}{cccc}
\hline & $\begin{array}{c}\text { Radical or } \\
\text { major } \\
\text { importance }\end{array}$ & $\begin{array}{c}\text { Significant } \\
\text { improvement }\end{array}$ & $\begin{array}{c}\text { Minor } \\
\text { importance }\end{array}$ \\
\hline $1967-73$ & 2.4 & 96.9 & 232.6 \\
$1974-79$ & 0.2 & 9.0 & 29.7 \\
$1980-82$ & 0.0 & 5.7 & 59.0 \\
\hline
\end{tabular}

Source: Authors' computations.

chemical industry. Moreover, the productivity data in table 1 also seem to indicate some recovery of growth in this industry after 1979. Thus the correlation between innovation and productivity performance evident in 1967-73 and 1974-79 is continued after 1979. However, we are unwilling to put much weight on such a short, turbulent period and will wait to see what future years demonstrate.

\section{TEXTILE INNOVATIONS}

Table 6 reports the basic data for the textile industry, defined as SIC 22. The most important component of innovation for textile productivity, new equipment, maintained continued vigor after 1973, the result of new generations of machinery that have consistently raised weaving and spinning speeds and reduced the labor required for restart.

The table does show some decline in the total number of process innovations. In the textile industry, however, in contrast to the chemical industry, when the process innovations are classified by type, as in table 7 , we find no decline in the flow of productivity-enhancing process innovations. The data in tables 6 and 7, therefore, provide important support for the link between innovation and productivity performance. After 1973, the textile industry showed no slowdown either in productivity growth or in its two main production-related categories of innovation-equipment and productivity-enhancing processes.

The other innovation categories in table 6 do decline somewhat after 1973. The drop-off in instrument innovations is not of great significance. Based on historical experience, the decline in the flow of new fibers could have been expected to be more important because changes in fiber have played a major role in textile productivity in the past. But the shift 
Table 6. Innovations in the Textile Industry, Selected Periods, 1967-82

Average number per year

\begin{tabular}{cccccc}
\hline Period & Equipment & Processes & Instruments & Fibers & $\begin{array}{c}\text { Dyes and } \\
\text { finishes }\end{array}$ \\
\hline $1967-73$ & 134.5 & 17.4 & 53.9 & 19.0 & 267.0 \\
$1974-79$ & 140.5 & 14.8 & 44.3 & 11.0 & 299.5 \\
$1980-82$ & 154.3 & 9.3 & 37.7 & 4.0 & 180.0 \\
\hline
\end{tabular}

Source: Authors' calculations. See text description.

from natural to man-made fibers that has been crucial to productivity growth continued rapidly throughout the 1970s and thus diminished the significance of the decline in the number of new man-made fibers after 1973. This development is discussed in more detail below.

\section{THE RESPONSE OF INNOVATIONS TO DEMAND}

Although the correlation between the patterns of productivity and innovation for the two industries is clear, the direction of causality is open to question. Jacob Schmookler has argued that innovation responds to demand rather than being driven by exogenous developments in technology. ${ }^{13}$ One might conjecture that weak demand after 1973 adversely affected both innovation and productivity.

It is true that recessions delay some new product introductions and that low investment reduces the productivity impact of process and equipment innovations. But the simple facts of the chemical and textile industries do not fit the Schmookler view. Both chemicals and textiles experienced weak demand after 1973. But one industry had low innovation and productivity growth, and the other did not. The differential experience of the two industries is not explained by demand.

\section{Two Industry Case Studies}

We now turn to more detailed case studies of the chemical and textile industries to explore more carefully whether innovation is the primary source of productivity growth; whether innovation has actually slowed and if so, why; and what other major influences there are on productivity and how they have changed.

13. Jacob Schmookler, Invention and Economic Growth (Harvard University Press, 1966). 
Table 7. Process Innovations in the Textile Industry, by Type, Selected Periods, 1967-82a

Average number per year

\begin{tabular}{cccc}
\hline & \multicolumn{3}{c}{ Type of innovation } \\
\cline { 2 - 4 } Period & $\begin{array}{c}\text { Productivity- } \\
\text { enhancing }\end{array}$ & $\begin{array}{c}\text { Environment- } \\
\text { related }\end{array}$ & $\begin{array}{c}\text { Energy- } \\
\text { related }\end{array}$ \\
\hline $1967-73$ & 4.4 & 0.7 & 0.3 \\
$1974-79$ & 5.0 & 1.0 & 0.7 \\
$1980-82$ & 4.3 & 0.3 & 0.0 \\
\hline
\end{tabular}

Source: Authors' calculations. See text description.

a. Categories are not exhaustive. See note to table 3 .

The sources of information for the case studies include in-depth interviews with personnel in major companies in both the chemical and textile industries, as well as studies prepared by others. Both industries have been studied exhaustively by economists, government agencies, and investment houses, so there is no shortage of information. Many of the secondary sources also used company interviews.

Clearly, a small number of interviews cannot provide a statistical sample for hypothesis testing in a formal way. In any case, these questions are probably not amenable to direct quantitative testing. Rather, the case studies will suggest answers to the questions posed.

The interviews were formalized to the following extent. Meetings were set up with both technical R\&D personnel and plant managers. Notes from the interviews were written up into narrative summaries that were submitted to interviewers for comments on accuracy and completeness. ${ }^{14}$ Although a formal questionnaire was not administered, all those surveyed were asked about innovation and productivity growth and the relationship between them over the past fifteen to twenty years. They were asked in general about reasons for any reported trends and asked specifically about the importance of such factors as energy prices, regulation, work effort, and foreign trade.

\section{THE CHEMICAL INDUSTRY}

The great majority of output in the chemical industry consists of bulk or commodity chemicals. ${ }^{15}$ Bulk chemicals include building block chem-

14. Copies of the summaries are available from the authors.

15. Major secondary sources of information for this industry include First Boston Corporation, Analysis of Chemical Production Capacities (Boston, 1977), and U.S. 
icals, such as benzene and ethylene, that are used in later chemical processes; organic intermediates, such as formaldehyde and methanol; and final-use chemicals, such as fibers (nylon, polyester), plastics (polyethylene, polyvinyl chloride), inorganic chemicals (soda, chlorine), and fertilizers (ammonia, phosphates), that are shipped out of the chemical industry. The remainder of the output comes from specialty companies. We interviewed employees of two large producers of bulk chemicals, Du Pont and Monsanto Co., and of one specialty company, the Minnesota Mining and Manufacturing Corp., 3M.

Bulk Chemical Companies. Employees at both Du Pont and Monsanto confirmed that productivity had slowed after 1973 and that the pace of innovation had declined in the 1970s. Both companies used internal productivity measures based on gross output per employee. Estimates of the slowing in the pace of innovation were more subjective. Virtually everyone with whom we spoke confirmed the existence of a slowdown, but R\&D staff generally described it as less significant than did the production staff. R\&D staff blamed the slowdown on shrinking $R \& D$ budgets in the early 1970s. Other staff indicated that the R\&D budgets were cut because the technological opportunities were limited. At the end of World War II immense technological opportunities awaited exploitation, partly as a result of developments stimulated by the war itself and partly because of a natural cycle in the technology of the industry, but by the 1970s research efforts were running into diminishing returns. A new impetus to technological development was needed.

Du Pont discovered nylon in 1935. Its commercial development was delayed by the war, but its discovery spawned a whole series of innovations falling in two waves, one in the 1950s and one in the 1960s. These innovations were not limited to new fibers, because the new chemistry stimulated by nylon led to many other applications. Five thousand new polymers were developed in the first wave alone. In the 1950s and 1960s, process innovations went along with the new product development, and successive generations of new process technology produced large productivity gains. Although Du Pont used patent protection and very restricted access to information in order to maintain a technological lead in production methods, by the 1970s the waves of

Department of Commerce, The U.S. Plastics and Synthetic Materials Industry Since 1958. Innovation in the chemical industry has been studied extensively in the research program headed by Edwin Mansfield at the University of Pennsylvania. 
innovation had run their course, and the opportunities for rapid advance in existing product lines were limited.

Monsanto achieved rapid productivity gains until 1970 primarily by building larger and larger plants. ${ }^{16}$ By the 1970 s, however, the potential for scale-related design and materials innovations had largely been exhausted.

According to staff at both companies, there is a very close link between innovation and productivity growth in the long run. In the short run, organizational and managerial changes and improvements in work practices can make a substantial difference. But even these improvements come as part of the learning curve associated with new products and processes. If a company were to fail to make innovations, productivity growth would slow and stop after a few years. The consensus at both companies was that the slowing in the pace of innovation had contributed significantly to the slowdown in productivity growth. The interview responses thus provide independent support for the quantitative results given earlier.

When asked about other causes of the productivity growth slowdown after 1973, interviewees cited slow growth in product demand as being at least as important as the slowing of innovation. In neither company was the slow growth in demand due primarily to the business cycle, although obviously the recession of 1974-75 did play a role. The two main causes cited for slow demand growth were structural-foreign trade and energy prices. The reduced number of product innovations itself also curbed demand growth.

Although the U.S. chemical industry does face direct foreign competition, the source of its trade difficulties was not its own foreign competition, but that of its customers. The textile and apparel industries, heavily affected by foreign competition in the 1970s, sharply reduced the growth rate of their purchases of chemicals, particularly synthetic fibers. ${ }^{17}$ At the same time, petrochemicals suffered from the increased

16. This interaction between innovation and economies of scale in the chemical industry has been analyzed by Richard C. Levin, "Technical Change and Optimal Scale: Some Evidence and Implications," Southern Economic Journal, vol. 44 (October 1977), pp. 208-21.

17. It should be stated for the record that Du Pont staff said that they were ready and willing to operate under a regime of free trade, provided they were free to sell fiber to whoever is producing textiles. Because of the multi-fiber agreement and various trade restrictions, they are not allowed to compete freely overseas. 
cost of oil and natural gas feedstocks, which raised final prices and caused a sharp reduction in demand growth. ${ }^{18}$

In both companies, the view was that the change in the trend of demand growth had an impact on their productivity for as long as ten years. Interviewees acknowledged that they had been slow to realize that the trend had changed. Because of the several-year-long planning and construction period for new chemical plants, large-scale state-ofthe-art plants, designed to achieve economies of scale and maintain or increase market share, continued to be brought on line even when company officials recognized that demand had fallen. These plants were then operated below capacity and thus very inefficiently, production worker requirements in such plants being almost independent of output levels. ${ }^{19}$

Specialty Chemical Companies. In addition to the producers of bulk chemicals, the chemical industry features smaller specialty companies. The large diversified companies, too, have specialty chemical divisions. We interviewed employees of $3 \mathrm{M}$, a company that produces a great many different chemicals, about half of which are sold internally to its other divisions. Those interviewees described 3M's experience in the 1970 s as being very different from that of the large-scale producers.

The chemical operations at $3 \mathrm{M}$ are not very capital-intensive. A specialist in versatility, $3 \mathrm{M}$ is the sole source of many of its products, and in some cases it produces the entire year's output in one or two days. The equipment is then cleaned and used for another chemical. Because of the diversity of products, 3M's internal productivity numbers are of limited value, but employees judged that there had been little or no productivity slowdown after 1973. Pursuing their traditional innovation strategy of making continual product improvements or developing new products related to existing ones, they sensed no slowdown in the pace of those innovations in the 1970s. Nor did the company experience excess capacity after 1973. As demand growth slowed, 3M followed a strategy of minimizing investment expenditures and making more efficient use of their plants.

18. The recession cut demand after 1973 , and then feedstock prices increased as price controls were lifted.

19. There is actually very little direct labor used in a large chemical plant. The problem of excess labor apparently included additional sales and clerical staff hired in anticipation of sales volume growth. 
Although the experience of this specialty chemical company and that of the bulk producers differ sharply, they are not inconsistent. The specialty company suffered no slowdown in innovation, no slowdown in productivity, and no excess capacity.

Other Causes of the Productivity Slowdown. Employees of the three companies also responded to questions about other possible causes of the decline in productivity growth. None thought that labor quality, work effort, or related labor issues had played an important role in changes in the trend of productivity growth. One company reported labor conflict occurring for a short period around 1975.

The problems associated with excess capacity are, of course, linked to capital services. But beyond this, none of the interviewees reported that accelerated obsolescence had been a major difficulty for their company, although employees of all three cited examples tied to either regulation or energy costs.

The diversion of $R \& D$ resources to meeting environmental regulatory requirements or to saving energy was important for Monsanto and $3 \mathrm{M}$, less so for Du Pont. For the period 1973-79 half of Monsanto's R\&D was environment- or energy-related. This draining of resources contributed to the decline in the number of cost-reducing innovations.

\section{THE TEXTILE INDUSTRY}

The textile industry is structured very differently from the chemical industry. ${ }^{20}$ It consists of a very large number of firms, most of them small. There were 6,000 U.S. textile companies in 1973, the largest of which, Burlington Industries, Inc., had 5 percent of the market. The next largest, J.P. Stevens and Co., had 3 percent in 1979. ${ }^{21}$ Plant sizes, too, are often small: in 1979, 70 percent of the plants had fewer than 100 employees. Many of these small plants and companies subcontract for

20. Major secondary sources for this industry include The U.S. Textile Mill Products Industry: Strategies for the 1980's and Beyond (Center for Industrial Policy and Strategy, University of South Carolina, 1982); U.S. Bureau of Labor Statistics, Technology and Manpower in the Textile Industry of the 1970's, Bulletin 1578(GPO, 1968); The Competitive Status of the U.S. Fibers, Textiles, and Apparel Complex (Washington, D.C.: National Academy Press, 1983).

21. See The U.S. Textile Mill Products Industry, p. 5-1a, pp. 5-27, and Gordon P. Yale, The Textile Industry in Transition, Report 532 (Stanford Research Institute, 1974), p. 1. 
the larger companies in what is called "jobbing"-performing such specific tasks as finishing the woven fabric.

We interviewed employees of two of the larger companies in the industry, as well as staff at the Philadelphia College of Textiles and the Textile Research Institute in Princeton. The latter were able to provide information about both large and small companies in the industry. Partly because many textile companies are privately owned and release little information, and partly because of political negotiations that were proceeding on textile quotas at the time of this study, the companies asked not to have their names associated with particular views. Interested readers may contact us for further information about the specific companies interviewed.

Both industry personnel and secondary sources agree that the rate of innovation and productivity growth in textiles remained strong in the 1973-79 period. Again, there is confirmation of the pattern we reported in our own data.

The industry experienced very rapid output and demand growth until the late 1960s and early 1970 s, when foreign competition began to erode market growth. Textile exports were reduced, and imports of foreignmade apparel increased. The textile industry itself, however, still had a trade surplus in 1981.

Unlike the chemical industry, the textile industry adapted to the change in growth without creating persistent excess capacity. The older and less efficient plants were closed, and employment fell rapidly. One company reported that it had actually increased its capital utilization in the 1970s, moving to seven-day-a-week, three-shift operation in order to minimize investment requirements. Differences in the technology account for the ability of the textile industry to adjust to lower output growth. ${ }^{22}$ The companies do not have large capital-intensive processbased plants and do not build much ahead of demand. Textiles and chemicals also have different labor relations traditions. Textile companies do not engage in much labor hoarding.

One of the important sources of rapid and continuing productivity growth cited by interviewees-the shift from natural to man-made fibers-was not well reflected in the innovation data. The production of

22. The textile industry has high average variable costs and low fixed costs relative to the chemical industry. 
textiles from natural fibers requires numerous steps before the yarn is woven. For cotton fabrics, for example, the cotton bales must first be broken up and the cotton fibers loosened and then blended. In the next step, "cording," the fibers are cleaned and formed into strands. Three more steps take place before spinning: "drawing" the fibers, "winding", the strands, and "roving," which reduces the size of the strands and winds them into fibers ready for spinning. After spinning, the yarn must still move to the "winding and warping" step before it is ready for weaving.

Synthetic fibers, provided by the chemical industry, often bypass the stages before spinning and are sometimes even spun in chemical plants before being sold. Moreover, because of their special physical properties, synthetic fibers can be spun and woven at very high speeds. These efficiently produced new fibers took over the market. In 1957 cotton and wool made up 71 percent of all U.S. fiber consumption. The proportion had fallen to 56 percent by 1966 and to 24 percent by 1981 . Textile industry productivity growth was thus boosted throughout the 1970 s by the waves of product innovation in the chemical industry that took place in the 1950s and 1960s. It is worth noting that foreign trade contributed to this productivity enhancement. In 1981, the United States had a substantial net trade surplus in man-made yarn and fabric and a substantial deficit in cotton fabric. The U.S. textile and apparel industries have maintained their comparative advantage most effectively in synthetic fabric.

Successive generations of new equipment have also continued to raise textile productivity growth. Carrying out only a small amount of R\&D itself, the industry has had access to a constant flow of new technologies, generated primarily from equipment suppliers. The latest Swiss Sulzer automatic looms can now weave 760 meters of denim a minute, nearly four times the speeds achieved twenty years ago. ${ }^{23}$ Developments in spinning technology have been just as dramatic. Air jets are replacing spindles, just as they earlier replaced shuttles. Circulating air currents now spin the yarn into thread.

Other developments in the industry that might have affected productivity were noted by the interviewees. Old capital became rapidly obsolete in the 1970s as new equipment was installed and old plants

23. Figures are from the Economist (27 July-2 August 1985), p. 82. 
closed. Labor quality and work effort had no major influence on productivity trends. Increased foreign competition encouraged management to introduce more productive work practices, benefiting productivity in the past ten years. The industry has been affected by economic regulation, particularly by Occupational Safety and Health Administration requirements for a clean work environment. Regulation did not cause a particular productivity slowdown in the 1970 s, however, because the regulations in this area were introduced in the 1960s and then strengthened over time. Finally, new generations of machinery are more energy-intensive than prior machinery.

\section{Consistency with Existing R\&D Studies}

We have found a striking pattern of declining innovation in the chemical industry that supports the hypothesis that the recent slowdown in trend productivity growth in U.S. manufacturing was caused to an important extent by a slowing of innovation. Our findings, however, appear to contradict empirical studies of R\&D spending across firms or industries that find no reduction of the impact of $R \& D$ on productivity after 1973. ${ }^{24}$ We first examine these other studies and then explain why we find our own results more persuasive.

The empirical studies in question look at a cross section of firms or industries before and after 1973. They estimate the extent to which R\&D has contributed to cross-sectional differences in either the level or the rate of growth of productivity, and they find that this contribution did not diminish significantly after 1973 . For example, the study by Zvi Griliches estimates a Cobb-Douglas production function:

$$
\ln Q_{\mathrm{i}}=\ln A+\alpha \ln K_{\mathrm{i}}+\beta \ln L_{\mathrm{i}}+\gamma \ln R_{\mathrm{i}} ; \quad \mathrm{i}=1, \ldots \mathrm{n},
$$

where $Q$ is output, $A$ is a constant, $K$ is capital, $L$ is labor, and $R$ is an estimate of the stock of R\&D capital, computed from annual R\&D expenditures just as the capital stock is computed, assuming some

24. F. M. Scherer, "Inter-Industry Technology Flows and Productivity Growth," Review of Economics and Statistics, vol. 64 (November 1982), pp. 627-34; Zvi Griliches, "Productivity, R\&D, and Basic Research at the Firm Level in the 1970s," Working Paper 1547 (National Bureau of Economic Research, January 1985). 
depreciation rate. The subscript runs over firms and the relation is estimated separately for 1967,1973 , and 1977. Griliches finds $\gamma$ rises somewhat from 1967 to 1973, and then falls again in 1977, but these changes are not significant.

The basic issue of interpretation is whether a decline in technological progress would necessarily show up in the coefficient $\gamma$ in a crosssectional regression. It is not obvious that the $R \& D$ elasticity is a function of opportunities. It is true that $R \& D$ works in conjunction with the set of such opportunities to increase knowledge and hence productivity. But capital and labor also work together to produce output. And changes in, say, labor-force quality would not necessarily affect the capital elasticity. Suppose "technology" is instead a separate factor of production. Then, since this variable has been omitted from the regressions, changes in it will be imputed to shifts in the constant, not to R\&D.

The second issue of interpretation, one that reinforces the first, concerns the way a slowdown in technology might strike across firms. Consider two examples. In the first, $R \& D$ spending is completely exogenous, and the slowdown strikes randomly across firms, hitting some and not others. In the second, the slowdown strikes in the same way, but spending responds quickly to changes in opportunities. In the first example there is no statistical reason why a slowdown would disturb the relation of firm R\&D stocks to productivity. In the second example, one would expect that the firms that were hit by a slowdown would cut the amount of their R\&D spending, while those in which prospects remained good would maintain spending. The total quantity of $R \& D$ spending would fall, but not necessarily the return to R\&D. ${ }^{25}$

The results from the $R \& D$ studies are certainly at odds with our evidence that technological opportunities have declined. At this point, however, there is no established market model that determines how $\mathrm{R} \& \mathrm{D}$ spending responds to a slowdown, and no established slowdown model that indicates how the slowdown hits across firms or industries. Without these models, we prefer to accept the direct evidence of the innovation data.

25. This point is also made by F. M. Scherer in " $R \& D$ and Declining Productivity Growth," American Economic Review, vol. 73 (May 1983, Papers and Proceedings, 1982), pp. 215-18. 


\section{An Overall Assessment}

It has been known for over twenty years that much of the observed increase in labor productivity growth over time was attributable directly to technical change, rather than to capital accumulation. Thus when growth slowed, it was natural to expect that a slowing of technical change was part of the reason. The evidence of this paper supports that view. Case studies of two major industries find a clear relation between their innovation and productivity patterns.

While we recognize the importance of looking at more industries to confirm the pattern, the evidence so far suggests that the productivity slowdown in U.S. manufacturing was caused by a combination of two basic forces. Innovation slowed down, and slow output growth caused resource underutilization in capital-intensive process industries.

Innovation slowed because of the exhaustion of technological opportunities that had opened up after World War II, but it did not slacken equally in all industries. The slowdown had more severe productivity consequences in capital-intensive industries, where innovative processes often involve larger scale production. The technical limits of this approach to cost reduction were being reached by the end of the $1960 \mathrm{~s}$ and sometimes even earlier, as in electricity generation. The plateau in technology may not be permanent. The chemical industry, for example, looks to biotechnology to provide a new wave of innovations in the 1990s.

The slowdown in output growth occurred partly because of the business cycle, but largely because of the kinds of structural shocks-in particular, growing foreign competition and higher energy prices-often cited in work on productivity.

Figure 1 illustrates a plausible slowdown scenario, combining the effects of slowing innovation and low utilization rates of plants. Ushaped cost curves are shown for successive generations of technology. The slowing of innovation is illustrated by the fact that the productivity increment in moving from the "first" to the "second" generation is greater than that in moving from the "second" to the "third." The cost reduction $A$ to $B$ is greater than that $B$ to $C$. Actual productivity performance is worse, however, because the third-generation capital is 
Figure 1. Innovation, Utilization, and Productivity ${ }^{a}$

Cost per unit
(inverse of productivity)

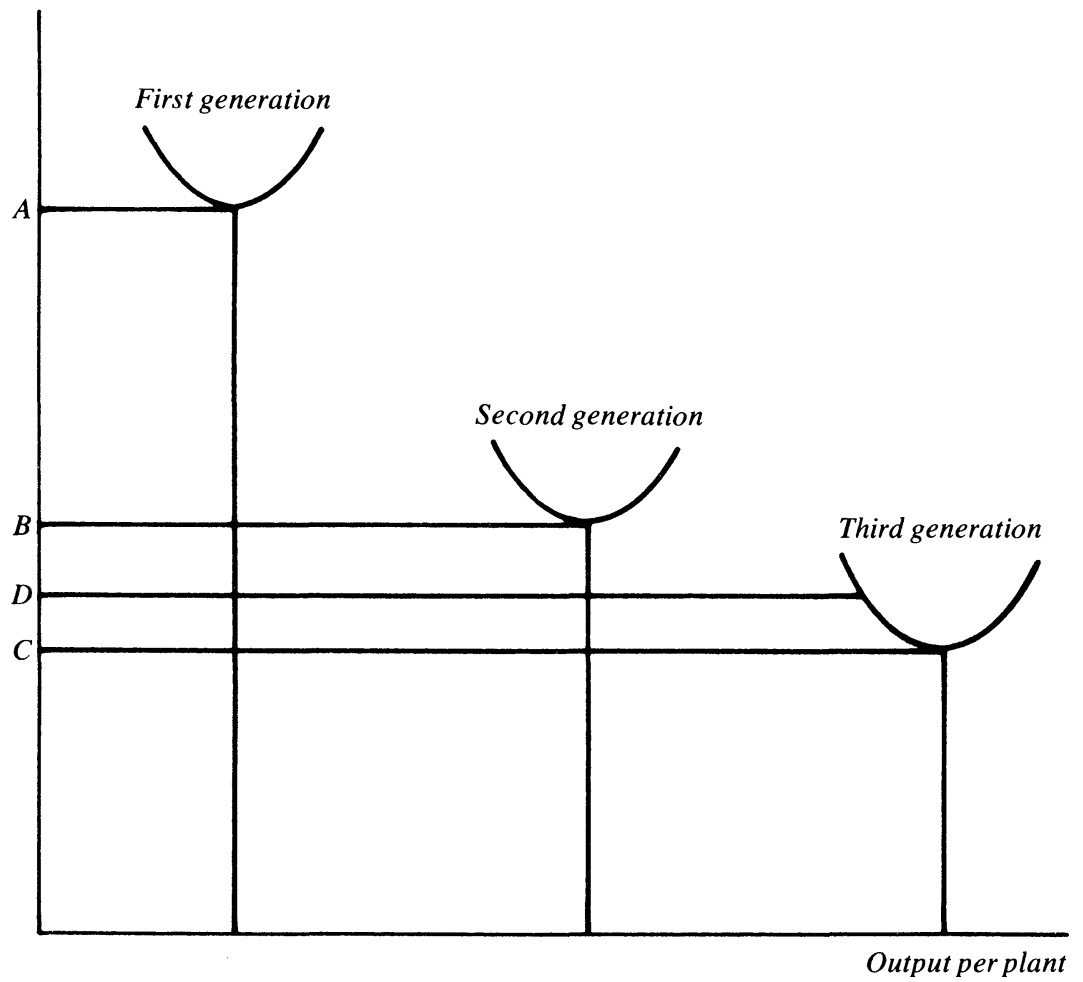

a. At "full" capacity the productivity gain is $A B$ from first to second generation, $B C$ from second to third. With excess capacity on third generation plants, the productivity gain falls to $B D$.

being inefficiently used. Thus the actual productivity gain in the third period is $B$ to $D$, not $B$ to $C$. This combination of developments appears to have characterized the chemical industry in the 1970 s.

The hypothesis that capital obsolescence is responsible for diminishing productivity growth, put forward in earlier work by Baily, receives little support from the cases studied in this paper, but the cases do illuminate some of the puzzles and patterns uncovered in that earlier work. Inefficient use of large-scale plants does imply a decline in capital services, one that shows up most in the capital-intensive process 
industries. Chronic underuse in the 1970s could also help explain the decline in the return to capital and its market value.

In future work we plan to study innovation and productivity in a major service industry. The big area of continued or accelerated innovation in the 1970s has been electronics. Apparently, the productivity benefits of computerizing white-collar activities have not been enough to offset the slowing of innovation in mature manufacturing industries. We hope to find out why. 


\section{Comments \\ and Discussion}

Richard C. Levin: It may seem surprising that it is still possible to make a useful contribution to understanding the productivity growth slowdown of the 1970s, but Martin Neil Baily and Alok Chakrabarti have done so. Unsatisfied that a full accounting can be rendered from the familiar lineup of suspects-energy price shocks, adjustment costs, depressed aggregate demand, inflation, and regulation-Baily and Chakrabarti have pressed on to examine whether the decline in productivity growth is at least in part attributable to a decline in the rate of innovation. Since, in their very labor-intensive efforts, they have looked at only two industries and found different answers in each, we can rest assured that the issue will remain unresolved for some time to come.

Baily and Chakrabarti are very much on the mark when they conclude that technological innovation may have declined despite the econometric evidence showing no perceptible decline in the rate of return to $R \& D$ or, alternatively, in the elasticity of output with respect to the stock of accumulated knowledge. When interindustry or intertemporal variations in technological opportunity-one important factor determining innovation-are not explicitly incorporated in the specification of a productivity growth equation, the estimated coefficient on R\&D can remain constant or even rise in the face of decreased technological opportunity.

The authors thus proceed to inquire whether the rate of technological innovation did in fact diminish in two industries: chemicals and textiles. The realized rate of innovation depends not only on the underlying opportunities for technical advance, but on many of the economic factors commonly invoked in explaining the productivity growth slowdown. There is a demand for new products and new processes as well as a supply. Thus, a finding that the rate of innovation has declined in a 
particular industry does not necessarily imply that the pool of technological opportunities has been depleted.

One has to applaud the authors for their painstaking efforts in developing several time series on innovations from articles in the trade periodicals of the two industries. But, for obvious reasons, such data can be misleading if not used carefully. All innovations are not alike. As analysis of patent data show, the distribution of innovations by economic value is highly skewed. Indeed, the vast majority of patents turn out to be worthless. Baily and Chakrabarti recognize the problem and attempt to resolve it by having experts rate the quality of innovations. Unfortunately, they report time series results using the quality-adjusted data for only one of the several categories of innovations they study (chemical processes). We should be wary of accepting conclusions about the other categories of innovation unless they are shown to hold for the subset of innovations judged to be at least significant improvements in technology.

Little that I know about the two industries studied gives me cause to quarrel with the specific findings of the authors' innovation counts and case studies. But I have one suggestion that may give rise to a reinterpretation of the data. The authors report a decline in productivityenhancing chemical process innovations after 1973, but only a slight decline in chemical process innovations related to environmental protection. This suggests that environmental regulation was not responsible for diverting innovative effort from productivity enhancement to pollution abatement. But I conjecture that a different pattern would appear if 1969, rather than 1973, were used as the end point of the first period. Once upon a time, in 1973 in fact, I surveyed the same chemical engineering journals consulted by Baily and Chakrabarti in connection with my work on scale-related technical change. My distinct impression was that precisely in 1970 there was a marked diversion of innovative activity from productivity enhancement to environmental protection.

I offer, also, additional evidence that bears on Baily and Chakrabarti's conclusions about the rate of innovation in the chemical and textile industries. In collaboration with Alvin Klevorick, Richard Nelson, and Sidney Winter, I recently conducted a survey of R\&D executives in 130 manufacturing industries. Our principal interests were to identify and measure interindustry differences in the ability of firms to appropriate returns from new technology, and to characterize interindustry differences in the nature and extent of technological opportunities. Several of 
our questions are closely related to the focus of the Baily-Chakrabarti inquiry. Although we did not ask explicitly whether either technological opportunities or the rate of innovation declined or increased during the 1980 s, we did ask respondents to assess whether the rate of introduction of new products and new processes since 1970 has been slow or rapid. We also asked whether the technological opportunities for introducing new products and processes are more or less favorable in the coming decade than they were in the 1970 s.

We worked at a more disaggregated level of industry detail than did Baily and Chakrabarti. Thus, we have distinct measures for a considerable number of chemical industries, including building-block industries (inorganic and organic chemicals), intermediate products (plastic materials, synthetic fibers, and synthetic rubber), and more specialized final products (fertilizers and pesticides). Unfortunately, we have no data on the textile manufacturing industry, though we do have responses from material suppliers (synthetic fibers) and equipment suppliers (textile machinery).

Table 1 presents some illustrative data. The data are industry mean responses to questions scored on a seven-point Likert scale: for innovation rates, the scale ranges from one, or very slow, to seven, or very rapid; for future opportunities compared with recent performance, the range is from one, or much worse, to seven, or much better.

The answers to our first pair of questions provide some support for the findings of Baily and Chakrabarti, although the reported innovation rates since 1970 must be compared cross-sectionally rather than with each industry's previous experience. In the basic chemical industries, respondents reported that the rate of product innovation since 1970 has been substantially slower than the average across all manufacturing industries. New process introductions have been less frequent than average in inorganic chemicals, though about average in organic chemicals. The rate of product innovation in synthetic fibers has been a bit better, but still below average. On the other hand, confirming Baily and Chakrabarti's conclusion that performance was better in specialty chemicals, we found a relatively rapid rate of product innovation in pesticides. And we also found support for the conclusions that the pace of textile machinery innovation may not have slackened, since the innovation rate in this industry was reported to have been better than average.

Another way to compare performance across industries is to sort the 
Table 1. Industry Mean Responses to Selected Survey Questions ${ }^{a}$

\begin{tabular}{lcccccc}
\hline & \multicolumn{2}{c}{$\begin{array}{c}\text { Rate of innovation } \\
\text { since } 1970\end{array}$} & & \multicolumn{2}{c}{$\begin{array}{c}\text { Current opportunities } \\
\text { compared to 1970s }\end{array}$} \\
\cline { 2 - 3 } Industry & Products & Processes & & Products & Processes \\
\hline Inorganic chemicals & 3.1 & 3.2 & & 3.9 & 3.9 \\
Organic chemicals & 4.0 & 4.0 & & 4.1 & 4.0 \\
Synthetic fibers & 4.2 & 3.6 & & 4.4 & 3.8 \\
Pesticides & 5.1 & 3.9 & & 4.8 & 4.6 \\
Textile machinery & 5.0 & $\ldots$ & & 5.0 & $\ldots$ \\
All industries & 4.5 & 4.0 & & 5.0 & 4.8 \\
\hline
\end{tabular}

Source: Questionnaire on industrial research and development, Yale University, Research Program on Technological Change. For a description of survey methods and preliminary results, see R. C. Levin, A. K. Klevorick, R. R. Nelson, and S. G. Winter, "Survey Research on R\&D Appropriability and Technological Opportunity" (Yale University, July 1984).

a. Questions scored on a seven-point Likert scale.

responses from the same 130 industries into quintiles. From this perspective, the pesticide industry falls into the highest quintile in the rate of product innovation. Textile machinery is in the second quintile, synthetic fibers is in the third, and organic and inorganic chemicals fall into the fourth and fifth quintiles, respectively.

In their conclusion, Baily and Chakrabarti imply that the source of productivity slowdown in other materials processing industries was similar to that of chemicals. It is certainly a reasonable conjecture that these capital- and energy-intensive sectors were particularly hard hit by increased energy prices and that they were particularly ill-suited to respond flexibly to decreased demand. It also turns out that their innovation experience since 1970 has paralleled that of the basic chemical industries. Primary aluminum, copper, lead, zinc, gypsum, cement, and petroleum refining all rank in the bottom quintile in the reported rate of product innovation. Steel is one quintile higher. And all these industries except petroleum and cement rank in the bottom two quintiles in the rate of process innovation.

Table 1 also summarizes the impressions of R\&D executives concerning the opportunities for continued technical advance. Technology forecasts, even by experts, should not be taken very seriously as predictions, but these data might be regarded as useful measures of interindustry differences in the degree of optimism about technological prospects. It is encouraging that across the spectrum of manufacturing industries, the average opinion is relatively optimistic. About two-thirds 
of our respondents rated the prospects for future product innovation as better than the opportunities available during the 1970s. Only 11 percent regarded future prospects as worse. Opinions concerning the opportunities for process innovation were only slightly less optimistic.

In the chemical industries, however, increased opportunities for innovation are not expected. This is somewhat surprising, given the potential application of biotechnology to chemical manufacturing processes, although respondents in the drug industry do expect increased opportunities. Elsewhere, materials processing industries generally do not foresee much improvement in technological opportunities, and some of the strong performers of the 1970s, notably semiconductors and communications equipment, have only an average degree of optimism. Optimism about future opportunities is strongest in two sectors: computers and instruments of all types.

\section{General Discussion}

William Nordhaus cited disaggregated survey work of the kind reported by Martin Baily and Alok Chakrabarti as an important step in sorting out the role that declining innovation may have played in the productivity slowdown. He characterized much previous work in this area as linking research inputs (R\&D spending) to productivity growth rates, without paying a great deal of attention to the black box between the two, and applauded the present work as an effort to look inside the black box. Nordhaus noted that Jacob Schmookler had put forth the view that innovation is driven by demand rather than being determined exogenously. Richard Levin added that two recent studies, one by Vivian Walsh and one by John Beggs, have called the Schmookler view into question. Neither of these recent studies found clear evidence that swings in the number of patents granted tracked swings in product demand. Instead, both studies supported the view that major innovations cause growth in demand for the products produced using the innovation, which in turn spawns a large number of patents representing follow-up improvements to the original innovation. Baily agreed that demand conditions may affect the pace of innovation; as an example, he mentioned that in the company interviews conducted for their study, he and Chakrabarti were told about one or two product innovations that were 
not introduced in 1975 because of weak demand. However, the major reason for the slowdown in the rate of innovation, according to those interviewed, was the shortage of technological opportunities.

George von Furstenberg suggested that one important difference between the textile industry and the chemical industry is that the textile industry is composed of many small firms, while the chemical industry is much more concentrated. One implication would seem to be that technological opportunities are largely given from the point of view of the individual textile firm, whereas they are apt to be endogenous from the point of view of the individual chemical firm. Von Furstenberg also suggested that the availability of licensing arrangements may have an important effect on the course of innovation. Levin noted that his own research suggests that the appropriability of returns from innovation does have a strong effect on the volume of innovation, though his results bear more on cross-industry differences in the volume of innovation than on the time series pattern of innovation.

Christopher Sims urged consideration of the role that factor price changes may have played in inducing innovation. Before 1973, Americans had spent decades figuring out how to use cheap energy, he noted; since the increases in energy prices, innovation has taken a decidedly different course. Daniel Mitchell pointed to data in tables 3 and 7 of the paper showing a substantial jump in energy-related innovations and a corresponding drop in productivity-enhancing process innovations in the chemical industry in the post-1973 period, but a much less marked jump in energy-related innovations and no drop in productivity-enhancing innovations in the textile industry. He found the difference suggestive of a diversion in R\&D effort in the chemical industry following the first oil price shocks.

Nordhaus noted that the value of innovations tends to be highly skewed; research done by Michael Scherer during the mid-1960s on the value of patents showed that only a few patents turned out to be very valuable. Just counting innovations may not adequately capture what has happened to innovative activity over time. Baily agreed with this observation, but noted that when the main categories of innovation in chemicals were classified by importance and by type, the evidence of declining innovation after 1973 remained strong.

James Duesenberry noted that there may be substantial lags between the introduction of an innovation and its eventual adoption by the 
majority of producers in an industry. Linking current innovation to current productivity growth, therefore, may be misleading; instead, one might expect a link between lagged innovation and current productivity growth. Baily responded that the data on innovation presented in the paper are probably best thought of as capturing the diffusion of major innovations. One good example is the introduction of air-jet and waterjet looms in the textile industry. These looms were first invented in the late 1960s; however, successive generations of innovations were needed to adapt them to production of various different fabrics. These later innovations are the ones being picked up in the Baily-Chakrabarti data for the 1970s.

Mitchell asked whether the pattern of productivity growth would look different if BLS volume of output measures were used in place of the gross domestic product data that appear in table 1. Baily stated his belief that the basic pattern would look similar with BLS data and commented that each of the available sources of productivity data has its strengths and weaknesses. The BLS data avoid problems related to the choice of an output price deflator; however, by using a gross production measure of output, these data ignore trends in the purchases of material inputs and services. 